\title{
Heterotypic protection of mice against chlamydial salpingitis and colonization of the lower genital tract with a human serovar $F$ isolate of Chlamydia trachomatis by prior immunization with recombinant serovar L1 major outer-membrane protein
}

\author{
Maureen Tuffrey, ${ }^{1}$ Frances Alexander, ${ }^{1}$ Wayne Conlan, ${ }^{2}$ Clare Woods ${ }^{1}$ and \\ MICHAEL WARD ${ }^{2 *}$ \\ ${ }^{1}$ Division of Sexually Transmitted Diseases, MRC Clinical Research Centre, Watford Road, Harrow, \\ Middx HA1 3UJ, UK \\ ${ }^{2}$ Molecular Microbiology Group, Southampton University Medical School, Southampton General Hospital, \\ Southampton SO9 $4 X Y, U K$
}

(Received 5 March 1992; revised 23 March 1992; accepted 13 April 1992)

\begin{abstract}
Intrauterine infection of mice with a human genital tract isolate of Chlamydia trachomatis (serovar F) resulted in salpingitis. In some cases, oviduct damage was sufficient to cause infertility due to lumenal blockage. Parenteral immunization with a purified, heterologous, recombinant major outer-membrane (rMOMP) preparation reduced the proportion of animals developing severe salpingitis by $77 \%$ compared with mock-immunized controls, but failed to reduce chlamydial colonization of the lower genital tract. In contrast, mice immunized with rMOMP directly into the Peyer's patches to stimulate mucosal immunity shed fewer chlamydiae from the vagina than controls, but showed little reduction in oviduct damage. No consistent correlation was observed between antibody levels to rMOMP in immunized mice and reduced lower genital tract colonization. Immunization with rMOMP via the presacral space, a route previously shown to stimulate mucosal immunity in the genital tract, produced high levels of circulating anti-rMOMP IgG but only traces of anti-rMOMP IgA in vaginal secretions. There was no difference in the severity of salpingitis in these animals compared with mock-immunized controls. Immunization with rMOMP conferred no protection against infertility resulting from direct inoculation of chlamydiae into the oviducts.
\end{abstract}

\section{Introduction}

The obligate intracellular pathogen Chlamydia trachoma$t i s$ is a major cause of sexually transmitted disease worldwide. In women, infection of the upper genital tract with chlamydiae is associated with pelvic pain and salpingitis which may lead to infertility or ectopic pregnancy (Chow et al., 1987; Robertson \& Ward, 1988). In large areas of the world $C$. trachomatis is the major infectious cause of female infertility. The cost of treating chlamydial infections and their sequelae runs to billions of dollars annually for the USA alone (Washington et al., 1987). In addition, C. trachomatis is also the world's

* Author for correspondence. Tel. (0703) 796991 ; fax (0703) 774316.

Abbreviation: rMOMP, recombinant major outer-membrane protein. major cause of preventable blindness (trachoma). An effective chlamydial vaccine is a major public health goal.

Empirical attempts to vaccinate against trachoma by immunization with whole $C$. trachomatis resulted in evidence of short-term, serovar-specific (homotypic) immunity to ocular chlamydial infection (reviewed in Taylor-Robinson \& Ward, 1989). Homotypic immunity would explain why repeat or multiple infections with $C$. trachomatis often involve immunologically distinct serovars (Barnes et al., 1986). Protective immunity following repeated infection with $C$. trachomatis would explain why active trachoma in endemic areas is essentially a childhood disease (Ward et al., 1990). However, delayedtype hypersensitivity responses to some chlamydial antigens, notably heat-shock proteins, may enhance disease severity (Morrison et al., 1989). Accordingly, attention has focused on the use of purified or 
recombinant chlamydial antigens for vaccine development. The major outer-membrane protein (MOMP) of C. trachomatis is the main candidate antigen.

MOMP, a porin, is the principal protein at the surface of the infectious chlamydial elementary body. MOMP may play a significant role in the entry of chlamydiae into the host cell (Su et al., 1988) and the initiation of intracellular development (Bavoil et al., 1984). Polyclonal and monoclonal antibodies directed against the serovar- or sub-species specific, surface-exposed antigenic epitopes on MOMP neutralize the infectivity of $C$. trachomatis in vitro and in vivo (Lucero \& Kuo, 1985; Zhang et al., 1987). The sub-species specific epitope should, thus, stimulate heterotypic immunity, while additional homotypic immunity should arise if the vaccine and challenge strain share the same serovarspecific epitope. The primary structures of these epitopes have been identified with high precision (Baehr et al., 1988; Conlan et al., 1988; Stephens et al., 1988). Moreover, recombinant MOMP (rMOMP) has been expressed at high levels in Escherichia coli (Pickett et al., 1988), facilitating the preparation of antigen in sufficient quantity for animal studies.

The present study was initiated in the mouse model of chlamydial salpingitis (Tuffrey et al., 1986a, 1990a) to explore whether rMOMP administered by routes associated with systemic or mucosal immune responses would elicit protective immunity against colonization or severe disease following challenge with heterotypic $C$. trachomatis.

\section{Methods}

Mice. Syngeneic $\mathrm{C} 3 \mathrm{H}$ mice, 6-8 weeks old, were bred and maintained in the specific-pathogen-free unit at the Clinical Research Centre (Harrow, Middx, UK) or were obtained from OLAC (HarlanOlac, Bicester, UK).

Chlamydiae. C. trachomatis strain NI 1, serovar F, was isolated from the endocervix of a contact of a man with non-gonococcal urethritis. For inoculation, chlamydiae from the ninth tissue-culture passage were suspended in $2 \mathrm{SP}$ cryopreservative $(68.5 \mathrm{~g}$ sucrose, $2.268 \mathrm{~g}$ sodium dihydrogen phosphate, $100 \mathrm{ml}$ foetal calf serum, water to $1000 \mathrm{ml}$ ). The inoculum was verified to be free of contaminating Mycoplasma or bacteria. Elementary bodies of $C$. trachomatis strain L1/440/LN, serovar $\mathbf{L l}$, were purified by density gradient separation as previously described (Salari \& Ward, 1981).

Preparation of recombinant MOMP. The cloning and expression of rMOMP was as previously described (Pickett et al., 1988). The $\frac{3}{4}-$ or $\frac{1}{2}$ length rMOMP (from the C-terminus) of $C$. trachomatis serovar L1 was purified from $E$. coli strain JM109 and adsorbed to alhydrogel as previously described (Conlan et al., 1990), except that in experiments 2 and 3 (see below) rMOMP was initially solubilized in $8 \mathrm{M}$-urea in buffer (25 mM-Tris/acetic acid buffer, pH 5, containing $1 \mathrm{mM}$-EDTA and $0 \cdot 1$ M-2-mercaptoethanol) before direct adsorption to alhydrogel for $1 \mathrm{~h}$ at room temperature at a ratio of $1 \mathrm{mg}$ rMOMP to $2 \mathrm{mg}$ alhydrogel. Yield of rMOMP from $E$. coli broth culture was approximately $35 \mathrm{mg} \mathrm{l}^{-1}$.
Vaccination of mice. Subcutaneous, intramuscular or intraperitoneal immunization with rMOMP was used to stimulate systemic immunity. Oral dosing with rMOMP, or direct inoculation into the presacral space or into surgically exposed Peyer's patches was used to induce mucosal immunity. Three experiments were performed. The numbers of mice used in each group are shown in the Tables. In experiment 1 , mice were immunized on days 0,14 and 21 with $20 \mu \mathrm{g} \frac{3}{4}$-length rMOMP which had been solubilized in $5 \%(\mathrm{w} / \mathrm{v})$ SDS prior to adsorption onto alhydrogel. Controls were inoculated with alhydrogel alone. Immunization was by one of three different routes. For parenteral immunization, each dose was divided between subcutaneous $(0.1 \mathrm{ml})$, intramuscular $(0.1 \mathrm{ml})$ and intraperitoneal $(0.2 \mathrm{ml})$ sites. To stimulate mucosal immunity, mice were inoculated directly into a surgically exposed Peyer's patch $(0.1 \mathrm{ml})$ or were dosed orally with a gavage needle with $0.05 \mathrm{ml}(25 \mu \mathrm{g})$ rMOMP on alhydrogel in $5 \%(\mathrm{w} / \mathrm{v})$ sodium bicarbonate. The mice were challenged by the intravaginal or intrauterine route with $C$. trachomatis strain NI 1 on day 28.

The second experiment focussed on mucosal immunity to ureasolubilized $\frac{3}{4}$-length rMOMP. Mice were inoculated directly into a surgically exposed Peyer's patch with $100 \mu \mathrm{g}$ rMOMP fragment on alhydrogel $(0.06 \mathrm{ml})$ on days 0,7 and 14 . A small sponge tampon containing a further $200 \mu \mathrm{g}$ rMOMP was inserted into the vagina on day 20 and removed on day 22 with the objective of inducing a secondary vaginal response to gut-primed mucosal immunity. One control group received topical intravaginal rMOMP without prior inoculation of Peyer's patches. A second control group was unimmunized. Vaginal washes were collected on days 23 and 28 prior to challenge with chlamydiae on day 30 .

The third experiment used urea-solubilized $\frac{1}{2}$-length rMOMP which is more readily expressed and purified than the $\frac{3}{4}$-length product. The experiment explored whether immunization of mice intraperitoneally or into the presacral space was effective at generating mucosal immunity. Groups of mice were immunized with $20 \mu \mathrm{g}$ urea-solubilized $\frac{1}{2}$-length rMOMP on alhydrogel on days 0,14 and 28 . Immunization was either by the oral, subcutaneous, or intraperitoneal routes or into the presacral space (Parr \& Parr, 1988), i.e. into the muscle that is attached to the ventral surface of the sacrum. For this latter injection the needle started between the base of the tail and the anus and passed about $8 \mathrm{~mm}$ towards the sacrum. Some mice were additionally given two intravaginal boosts with $50 \mu \mathrm{g}$ rMOMP (soaked into tampons) on days 32 and 44 . Immunized mice and untreated controls were challenged with chlamydiae on day 53 .

Infection of mice. All mice were given a single dose of $2.5 \mathrm{mg}$ progesterone subcutaneously (Depo-Provera; Upjohn, USA) $7 \mathrm{~d}$ prior to challenge with approximately $5 \times 10^{4}$ inclusion-forming units (i.f.u.) C. trachomatis strain NI 1 in 2SP diluent. Progesterone treatment is not essential, but enhances genital tract infection with chlamydiae by altering the oestrous cycle to maintain the target epithelium (Tuffrey \& Taylor-Robinson, 1981). Mice were challenged by one of three routes. In experiment 1 , the challenge dose $(0.05 \mathrm{ml})$ was introduced into the vagina soaked on a small sponge tampon to aid retention of the inoculum. Other groups of mice were inoculated directly into a uterine horn $(0.05 \mathrm{ml})$. For fertility studies, mice were inoculated into one or both of the ovarian bursae. Details of animal handling and surgical procedures have been published previously (Tuffrey et al., 1986a, $1990 \mathrm{~b}$ ). Relevant animal welfare legislation was strictly complied with.

Recovery of chlamydiae. Vaginal colonization was assessed using nasopharnyngeal swabs (Medical Wire and Equipment Co.) at regular intervals from days 4 to 33 (see Tables). Each swab was expressed in $1 \mathrm{ml}$ cold $2 \mathrm{SP}$ medium then stored in liquid nitrogen. Chlamydiae were cultured by centrifuge-assisted inoculation onto cycloheximide-treated McCoy cell monolayers by conventional procedures (Thomas et al., 1977). 
Antibody studies. Sera and cervical washes were obtained at various intervals after immunization and were stored at $-20^{\circ} \mathrm{C}$ until required. Samples from mice in the same group were pooled. Samples were collected one week after each of the 2nd and 3rd immunizations in experiment 1 , and 3 and $5 \mathrm{~d}$ after the intravaginal boost in experiment 2. In experiment 3 , samples were obtained $3 \mathrm{~d}$ after the 2 nd and $3 \mathrm{rd}$ immunizations and $5 \mathrm{~d}$ after each vaginal boost.

Antibodies to rMOMP, or to $C$. trachomatis strain $\mathrm{Ll} / 440 / \mathrm{LN}$ or NI 1 elementary bodies were detected by a redox-amplified ELISA (Ward et al., 1990) or by indirect immunofluorescence (Thomas et al., 1977).

Fertility studies. Intrabursal inoculation with $C$. trachomatis strain NI 1 was used for breeding studies because it results in a higher proportion of infertile mice than intrauterine inoculation, minimizing the number of laboratory animals required. Groups of challenged vaccinated or control mice were set aside for breeding. No vaginal swabs were taken from these animals so as to avoid any possible interference with their reproductive capacity. On day 14 after challenge ( $20 \mathrm{~d}$ after progesterone treatment) both vaccinated and control mice were placed with fertile males. Control groups were progesteronetreated mice inoculated with suspending buffer alone, plus a group of age-matched, progesterone-treated mice which had had no surgical intervention. The first vaginal plug was detected in the 2SP diluent control group, $10 \mathrm{~d}$ after placing with males, confirming that the oestrous cycle had recommenced following progesterone treatment.

Histology. Mice were killed between days 29 to 74 days after infection (experiment 1 ) or between 12 to 35 days post-infection (experiments 2 and 3). The oviducts and uterus on both sides were fixed in $10 \%(\mathrm{v} / \mathrm{v})$ buffered formalin before paraffin embedding. Sections $4 \mu \mathrm{m}$ thick were cut at various levels through the tissue and stained with conventional haematoxylin and eosin. Inflammatory changes were graded from - to +++ as described previously (Tuffrey et al., 1986a).

Electron microscopy. Mouse oviduct was processed for scanning electron microscopy as previously described (Tuffrey et al., 1990a). Specimens were examined at $20 \mathrm{kV}$ in a $2 \mathrm{~nm}$ resolution Hitachi $S 500$ scanning electron microscope equipped with a field-emission electron gun.

\section{Results}

\section{Effects of chlamydial infection on the oviduct of unimmunized mice}

The morphological effects of intrauterine challenge with $C$. trachomatis strain NI 1 are summarized in the scanning electron micrographs (Fig. 1). The mucosal surface of the normal mouse oviduct consists of both ciliated and non-ciliated epithelia (Fig. $1 a$ ). Fifteen days after challenge with strain NI 1 there was a severe loss of ciliated epithelial cells (Fig. $1 b$ ). This has been associated with impairment in transportation of eggs (Tuffrey et al., 1990a). The lumen of infected oviducts almost invariably contained an exudate (Fig. $1 c$ ), characterized by light microscopy (data not shown) as consisting of mucus, epithelial debris and the acute inflammatory cells characteristic of salpingitis. This exudate is frequently sufficient to block the oviduct lumen (Tuffrey et al., 1986b). Hydrosalpinx, characterized by severe ballooning of the oviduct (Fig. 1d) and further mucosal destruction, was observed in approximately half of the tubes.

\section{Re-isolation of chlamydiae from the lower genital tract in} test and control mice challenged by the intrauterine route

Chlamydial isolation rates for mice in experiment 1 , which had been vaccinated either parenterally or via a Peyer's patch with solubilized rMOMP adsorbed onto alhydrogel, were compared with control mice immunized with alhydrogel alone (Table 1). Chlamydiae were isolated from the genital tract on at least one occasion from 7 out of $8(88 \%)$ control mice and from 4 out of 6 $(67 \%)$ of the parenterally vaccinated mice. Chlamydial colonization was reduced from 25 to $15 \mathrm{~d}$ in the parenterally immunized mice compared to controls. Immunization with rMOMP into surgically exposed Peyer's patches delayed vaginal colonization with chlamydiae by $5 \mathrm{~d}$ in the test animals compared with controls. Overall, the number of mice from which chlamydiae were recovered on at least one occasion was also reduced in the immunized animals from 7 out of 8 $(88 \%)$ compared to 5 out of $8(63 \%)$ in the control group. Moreover, in the latter group chlamydiae were isolated on only one occasion when, generally, only a single inclusion body was seen. A total of 383 i.f.u. were recovered from the six control mice found to be infected with chlamydiae over the first $11 \mathrm{~d}$, but in the same period only 7 i.f.u. were recovered from the three mice found to be infected with chlamydiae following immunization with rMOMP via a Peyer's patch. Thus immunization of the gut with heterotypic serovar L1 rMOMP via the Peyer's patches markedly reduced vaginal shedding of C. trachomatis, strain NI 1, serovar F.

\section{Mice challenged by the intravaginal route}

In the natural infection, vaginal colonization precedes ascending chlamydial infection of the upper genital tract. The oral and Peyer's patch routes of mucosal immunization were less effective against intravaginal challenge than against intrauterine challenge (cf. Tables 1 and 2). There was no evidence of protection against intravaginal challenge in mice immunized via surgically exposed Peyer's patches, and only weak evidence of protection in mice orally dosed with rMOMP. In the orally immunized group, 13 out of $14(93 \%)$ animals and $39 \%$ of swabs were positive for chlamydial isolation in the control mice compared with 8 out of $13(62 \%)$ and $22 \%$, respectively. 

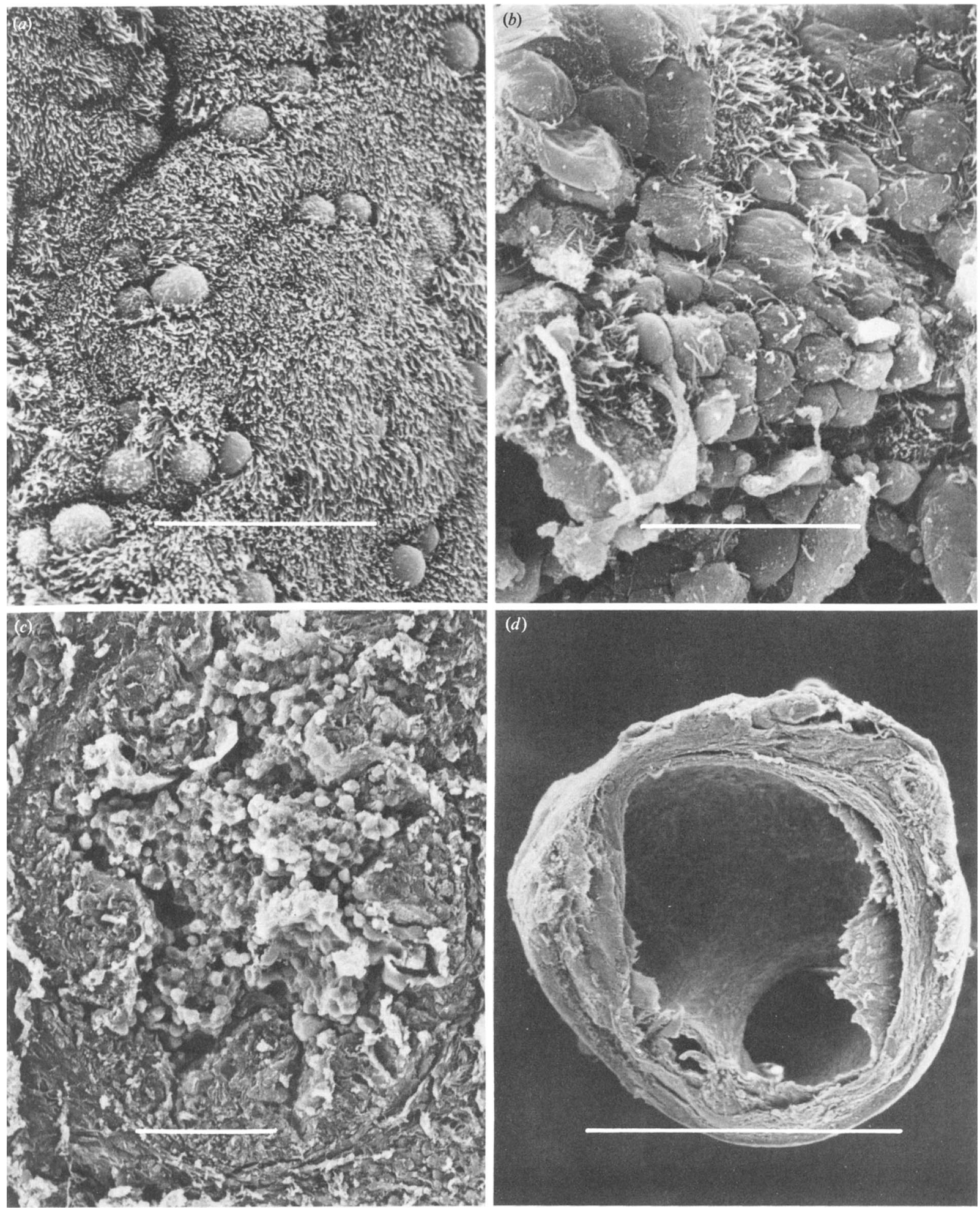

Fig. 1. Scanning electron micrographs showing the effects of infection with $C$. trachomatis strain NI 1 on the epithelial surface of the mouse oviduct. Twenty control or infected oviducts were examined. (a) Normal, uninfected oviduct showing ciliated and non-ciliated epithelium. The bar represents $20 \mu \mathrm{m}$. (b) The lumenal epithelium of the oviduct $15 \mathrm{~d}$ after intrauterine infection with $C$. trachomatis strain NI 1. Note the denudation of the ciliated epithelium and the presence of surface debris. The bar represents $20 \mu \mathrm{m}$. (c) Transverse section of murine oviduct $15 \mathrm{~d}$ after intrauterine infection with chlamydiae showing blockage of the lumen with cellular debris. The bar represents $50 \mu \mathrm{m}$. (d) Transverse section of an oviduct with hydrosalpinx, $27 \mathrm{~d}$ after intrauterine infection with $C$. trachomatis strain NI 1. The bar represents $0.5 \mathrm{~mm}$. 
Table 1. Vaginal colonization of vaccinated and control C3H mice after intrauterine challenge with $C$. trachomatis strain NI 1

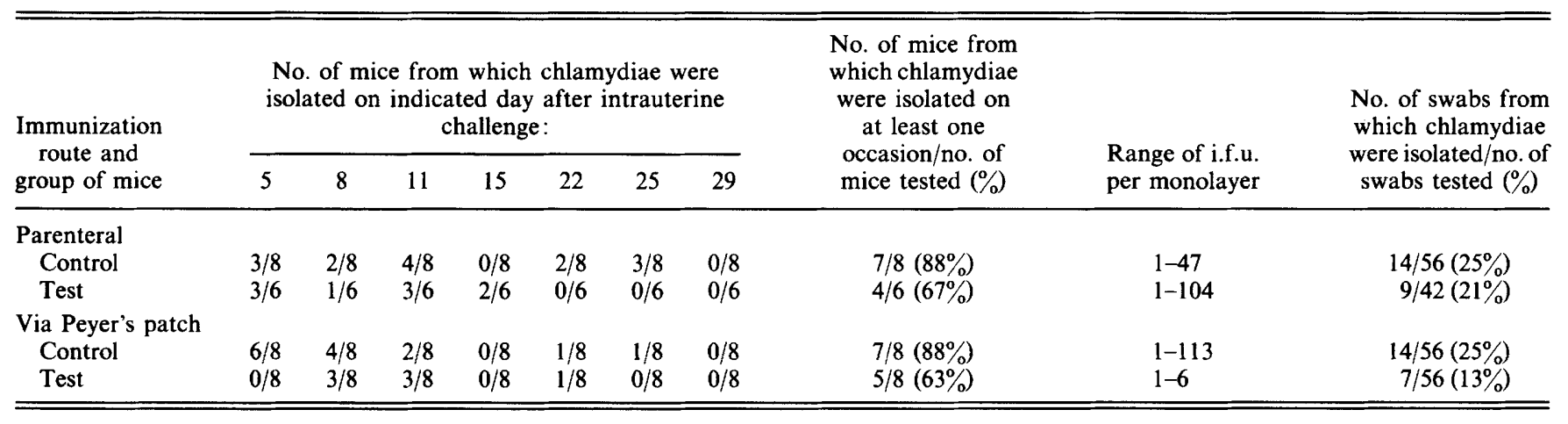

Table 2. Vaginal colonization of vaccinated and control C3H mice after intravaginal challenge with C. trachomatis strain NI 1

\begin{tabular}{|c|c|c|c|c|c|c|c|c|c|c|}
\hline \multirow{2}{*}{$\begin{array}{l}\text { Immunization } \\
\text { route and } \\
\text { group of mice }\end{array}$} & \multicolumn{7}{|c|}{$\begin{array}{c}\text { No. of mice from which chlamydiae were } \\
\text { isolated on indicated day after intravaginal } \\
\text { challenge: }\end{array}$} & \multirow{2}{*}{$\begin{array}{l}\text { No. of mice from } \\
\text { which chlamydiae } \\
\text { were isolated on } \\
\text { at least one } \\
\text { occasion } / \text { no. of } \\
\text { mice tested }(\%)\end{array}$} & \multirow{2}{*}{$\begin{array}{l}\text { Range of i.f.u. } \\
\text { per monolayer }\end{array}$} & \multirow{2}{*}{$\begin{array}{l}\text { No. of swabs from } \\
\text { which chlamydiae } \\
\text { were isolated/no. of } \\
\text { swabs tested }(\%)\end{array}$} \\
\hline & 5 & 8 & 11 & 14 & 20 & 23 & 32 & & & \\
\hline \multicolumn{11}{|l|}{ Oral } \\
\hline Control & NT & $9 / 14$ & NT & $3 / 13$ & $5 / 14$ & $8 / 14$ & $2 / 14$ & $13 / 14(93 \%)$ & $1-82$ & $27 / 69(39 \%)$ \\
\hline Test & NT & $8 / 13$ & NT & $2 / 13$ & $1 / 13$ & $2 / 13$ & $1 / 13$ & $8 / 13(62 \%)$ & $1-122$ & $14 / 65(22 \%)$ \\
\hline \multicolumn{11}{|c|}{ Via Peyer's patch } \\
\hline Control & $1 / 8$ & $4 / 8$ & $2 / 7$ & $0 / 8$ & $1 / 8$ & NT & NT & $6 / 8 \quad(75 \%)$ & $2-25$ & $7 / 30(18 \%)$ \\
\hline Test & $5 / 8$ & $2 / 8$ & $4 / 7$ & $0 / 8$ & $0 / 8$ & NT & $\mathbf{N T}$ & $7 / 8 \quad(88 \%)$ & $1-12$ & $11 / 39(28 \%)$ \\
\hline
\end{tabular}

NT, Not tested.

\section{Effect of immunization on salpingitis}

None of the mice inoculated intravaginally in experiment 1 developed salpingitis. In 10 years of experience of this mouse model salpingitis has not been observed following intravaginal challenge with $C$. trachomatis. Our data are, therefore, restricted to animals challenged via the intrauterine route. In experiment 1 , histological studies on oviducts 29 to $74 \mathrm{~d}$ after challenge (after the colonization study) showed that parenteral immunization with rMOMP reduced the incidence of late salpingitis from 4 out of $7(57 \%)$ in the control mice ( 3 out of 4 of which had hydrosalpinx) to 2 out of $6(33 \%)$ in the immunized mice (none of which had hydrosalpinx). When pairs of test and control mice killed on the same day were compared (Table 3), the lesions seen in control mice were more severe than those in the test mice in $50 \%$ of comparisons and of equal severity in $33 \%$ of cases. Immunization via Peyer's patches reduced chlamydial shedding, but as 3 out of 8 controls had inflammatory changes compared with 4 out of 8 test animals, this was not associated with a reduction in the prevalence or severity of salpingitis.

In experiment 2, the mice were killed from 12 to $24 \mathrm{~d}$ after intrauterine challenge, when salpingitis should be at its most severe. All mice immunized via the Peyer's patches developed salpingitis, although there was some evidence of a reduction in severity. No immunized animals had lesions that were more severe than in the unimmunized controls, while $44 \%$ of the immunized animals had less severe lesions. Taken together, these data indicate that the vaccine had a modest protective effect. Topical intravaginal rMOMP alone, failed to reduce the severity of the salpingitis.

In experiment 3, parenteral immunization with rMOMP had little effect on the prevalence of salpingitis 14 to $35 \mathrm{~d}$ after intrauterine challenge. Thus 7 out of 8 control mice had salpingitis, compared with 5 out of 8 mice immunized subcutaneously, 7 out of 8 immunized intraperitoneally, 6 out of 8 immunized orally and 8 out of 8 immunized by the presacral route. However, the salpingitis in immunized animals was again generally less severe than in control animals (Table 3), indicating some protection from rMOMP immunization. Salpingitis was less severe than in the controls in all mice immunized subcutaneously and in $75 \%$ of mice immunized intraperitoneally or orally with an intravaginal booster.

Table 4 summarizes salpingitis in the 55 pairs of control and test mice immunized with rMOMP in all 
Table 3. Oviductal histological changes in mice challenged after immunization (test) compared with those in mice after primary genital inoculation with chlamydial strain NI I (control)

Experiment 1 : immunized with $\frac{3}{4}$-length rMOMP; mice killed $29-74 \mathrm{~d}$ post-infection. Experiment 2 : mice killed 12-24 d post-infection. Experiment 3: immunized with $\frac{1}{2}$-length rMOMP; mice killed $14-35 \mathrm{~d}$ postinfection.

\begin{tabular}{|c|c|c|c|c|c|}
\hline \multirow[b]{2}{*}{$\begin{array}{l}\text { Experiment } \\
\text { no. }\end{array}$} & \multirow{2}{*}{$\begin{array}{l}\text { No. of pairs } \\
\text { of mice } \\
\text { (test versus } \\
\text { control) }\end{array}$} & \multirow[b]{2}{*}{$\begin{array}{l}\text { Immunization route and } \\
\text { schedule for test mice* }\end{array}$} & \multicolumn{3}{|c|}{$\begin{array}{c}\text { Histological evaluation of } \\
\text { salpingitis in pairs of mice (test } \\
\text { versus control) killed on the same } \\
\text { day } \dagger\end{array}$} \\
\hline & & & $\begin{array}{c}\text { Test } \\
\text { more } \\
\text { severe }\end{array}$ & $\begin{array}{c}\text { Test } \\
\text { less } \\
\text { severe }\end{array}$ & Same \\
\hline 1 & $\begin{array}{l}6 \\
8\end{array}$ & $\begin{array}{l}\text { s.c., i.p. and i.m. } \\
\text { Peyer's patch }\end{array}$ & $\begin{array}{l}1(17 \%) \\
2(25 \%)\end{array}$ & $\begin{array}{l}3(50 \%) \\
2(25 \%)\end{array}$ & $\begin{array}{l}2(33 \%) \\
4(50 \%)\end{array}$ \\
\hline 2 & 9 & Peyer's patch & 0 & $4(44 \%)$ & $5(50 \%)$ \\
\hline 3 & $\begin{array}{l}4 \\
4 \\
4 \\
4 \\
4 \\
4 \\
4 \\
4\end{array}$ & $\begin{array}{l}\text { s.c. } \\
\text { s.c. and i.vag. booster } \\
\text { i.p. } \\
\text { i.p. and i.vag. booster } \\
\text { Oral } \\
\text { Oral and i.vag. booster } \\
\text { Presacral } \\
\text { Presacral and i.vag. booster }\end{array}$ & $\begin{array}{l}1(25 \%) \\
1(25 \%) \\
1(25 \%)\end{array}$ & $\begin{array}{l}4(100 \%) \\
4(100 \%) \\
3(75 \%) \\
3(75 \%) \\
2(50 \%) \\
3(75 \%) \\
2(50 \%) \\
2(50 \%)\end{array}$ & $\begin{array}{l}1(25 \%) \\
2(50 \%) \\
1(25 \%)\end{array}$ \\
\hline Total & 55 & & $\begin{array}{l}7 \\
(12 \cdot 7 \%)\end{array}$ & $\begin{array}{l}32 \\
(58 \cdot 2 \%)\end{array}$ & $\stackrel{16}{(29 \cdot 1 \%)}$ \\
\hline
\end{tabular}

* Immunization route subcutaneous (s.c.), intraperitoneal (i.p.), intramuscular (i.m.) or intravaginal (i.vag.).

+ Inflammatory changes were graded from - to +++ as described by Tuffrey et al. $(1986 a)$.

Table 4. Comparison of immunization routes

\begin{tabular}{|c|c|c|c|c|}
\hline \multirow[b]{2}{*}{$\begin{array}{l}\text { Routes of } \\
\text { immunization } \\
\text { of test mice* }\end{array}$} & \multirow[b]{2}{*}{$\begin{array}{l}\text { No. of pairs } \\
\text { of mice (test } \\
\text { vs. control) }\end{array}$} & \multicolumn{3}{|c|}{$\begin{array}{l}\text { Histological evaluation of salpingitis } \\
\text { in pairs of mice (test vs. control) } \\
\text { killed on the same day }(\%) \dagger\end{array}$} \\
\hline & & $\begin{array}{c}\text { Test } \\
\text { more } \\
\text { severe }\end{array}$ & $\begin{array}{c}\text { Test } \\
\text { less } \\
\text { severe }\end{array}$ & Same \\
\hline $\begin{array}{l}\text { Parenteral routes } \\
\text { s.c., i.p. and i.m. }\end{array}$ & 22 & $2(9 \%)$ & $17(77 \%)$ & $3(14 \%)$ \\
\hline Peyer's patch & 17 & $2(12 \%)$ & $6(35 \%)$ & $9(53 \%)$ \\
\hline Oral & 8 & $2(25 \%)$ & $5(63 \%)$ & $1(13 \%)$ \\
\hline Presacral & 8 & $1(12.5 \%)$ & $4(50 \%)$ & $3(37.5 \%)$ \\
\hline
\end{tabular}

* See Table 3.

$\dagger$ Inflammatory changes graded as in Table 3.

three experiments. The aggregated results show that salpingitis in mice parenterally immunized with rMOMP was less severe than in the unimmunized controls in $77 \%$ of cases. By contrast, immunization with rMOMP via the Peyer's patch showed little reduction in the severity of salpingitis (Table 4), despite the associated reduction in chlamydial shedding (Table 1). Immunization via the oral or presacral routes, which was also designed to induce mucosal immunity, was also less protective than the parenteral route. Taken together, this suggests that the protective mechanisms reducing disease severity were not the same as those which reduced colonization.

\section{Effect of immunization on fertility following C. trachomatis challenge}

The fertility of unimmunized control mice, or of mice vaccinated with rMOMP either parenterally or via the Peyer's patches was compared over an 8 month period 
Table 5. Fertility in immunized and control $\mathrm{C} 3 \mathrm{H}$ mice 8 months after intrabursal challenge with C. trachomatis strain NI 1

\begin{tabular}{llc}
\hline \hline \multicolumn{1}{c}{$\begin{array}{c}\text { Immunization } \\
\text { schedule }\end{array}$} & \multicolumn{1}{c}{$\begin{array}{c}\text { Challenge } \\
\text { inoculum }\end{array}$} & $\begin{array}{c}\text { No. of mice litters/ } \\
\text { no. mice in group (\%) }\end{array}$ \\
\hline Untreated controls & None & $9 / 10(90 \%)$ \\
Parenteral alum & 2SP buffer & $5 / 6(83 \%)$ \\
Parenteral rMOMP & Unilateral NI 1 & $4 / 10(40 \%)$ \\
Parenteral alum & Unilateral NI & $2 / 10(20 \%)$ \\
Parenteral rMOMP & Bilateral NI 1 & $0 / 9 \quad(0 \%)$ \\
Alum via Peyer's patch & Bilateral NI 1 & $0 / 10(0 \%)$ \\
rMOMP via Peyer's patch & Unilateral NI 1 & $1 / 10(10 \%)$ \\
Alum via Peyer's patch & Unilateral NI 1 & $2 / 10(20 \%)$ \\
rMOMP via Peyer's patch & Bilateral NI 1 & $0 / 10(0 \%)$ \\
\hline \hline
\end{tabular}

following direct inoculation into the ovarian bursa with C. trachomatis strain NI 1. This route achieves the highest levels of infertility in unprotected animals (Tuffrey et al., 1986b). Control mice were inoculated with $2 \mathrm{SP}$ buffer alone or were uninoculated. A summary of the results is presented in Table 5 .

Of the untreated mice, 9 out of 10 gave birth to $1-3$ litters (average litter size $=5-6$ ) over the study period as did 5 out of 6 mice inoculated with 2SP buffer alone. No litters were born to any of the parenterally vaccinated or control-treated mice infected bilaterally with $C$. trachomatis strain NI 1 . Of the parenterally vaccinated animals in this group which had been challenged unilaterally, 2 out of 10 gave birth to 1 or 2 litters, whilst 4 out of 10 of the alhydrogel-treated controls in this group also littered. Thus, parenteral vaccination with rMOMP did not prevent infertility caused by chlamydial infection of the genital tract.

In mice immunized via the Peyer's patches, bilateral intrabursal inoculation with strain NI 1 rendered all 10 alhydrogel-treated controls in this group infertile and only 1 out of 9 mice vaccinated with rMOMP gave birth to a single litter of three offspring. Unilateral challenge with strain NI 1 also resulted in infertility in mice immunized via Peyer's patches and control mice. Of the alhydrogel control mice, 1 out of 10 gave birth to a single litter, whilst 2 out of 10 rMOMP-vaccinated mice also littered. Thus, prior immunization with rMOMP via surgically exposed Peyer's patches also failed to protect the fertility of mice with upper genital tract chlamydial infection.

\section{Antibody studies}

Sera and cervical washes were collected at various times following immunization with rMOMP adsorbed to alhydrogel or with alhydrogel alone. The most detailed antibody observations using conventional techniques (immunofluorescence) were carried out in experiment 3.
In this experiment, mice were immunized with rMOMP via the subcutaneous, intraperitoneal, oral or presacral routes with or without an additional intravaginal booster. Pooled serum samples and cervical washes from pairs of mice were taken on days 17, 31, 37 and 50, and antibody titres were determined by indirect immunofluorescence. Circulating IgG to both rMOMP and homologous serovar L1 elementary bodies was detected at similar levels in mice immunized via the intraperitoneal or presacral routes, with a mean titre of $1: 1024$ on day 37. Similar titres of IgG antibodies to rMOMP were detected in the mice immunized subcutaneously. These antibody titres were reduced by about one doubling dilution when strain NI 1 elementary bodies were used as antigen. No circulating IgG antibodies were found in the group immunized orally. Low levels of vaginal $\operatorname{IgA}$ were detected in imprint material from the antigen-soaked tampons from all groups assayed at day 46, except the subcutaneously immunized mice. IgG was present in tampon imprints from all groups.

\section{Discussion}

Parenteral immunization with rMOMP reduced the duration of colonization and also reduced the severity of inflammatory changes in the oviduct (salpingitis). This protective effect of parenteral immunization with rMOMP against salpingitis was unexpected. Previous studies in this model showed that prior chlamydial infection with live organisms was associated with more severe salpingitis (Tuffrey et al., 1990b), possibly as a result of delayed-type hypersensitivity responses to chlamydial heat-shock proteins similar to those observed in the guinea pig (Morrison et al., 1989). Reduction in the severity of salpingitis in animals parenterally immunized with rMOMP coincided with high levels of circulating IgG to the protein, although it is not known whether this association was significant. Parenteral immunization 
might promote antibody-dependent cell-mediated cytotoxic attack (ADCC) on cells infected with chlamydiae. However, it seems more likely that parenteral MOMP immunization sensitizes $T$ cells to chlamydial antigen, leading to the production of chlamydiastatic cytokines such as gamma interferon or tumour necrosis factor (Shemer-Avni et al., 1988). Salpingitis is one of the most significant complications of chlamydial genital tract infection because of its impact on fertility. Unfortunately, the reduced severity of salpingitis following parenteral immunization with rMOMP was insufficient to prevent infertility following direct inoculation of chlamydiae into the ovarian bursa. This severe and unnatural challenge probably overwhelmed the modest degree of protection achieved by parenteral immunization with rMOMP.

Direct immunization with rMOMP into the Peyer's patches was more effective at reducing chlamydial colonization than parenteral immunization, despite the absence of significant local antibody. Priming of the common mucosal immune system via the gut-associated lymphoid tissue (GALT) may not lead to the appearance of specific antibodies at distant mucosal surfaces in the absence of local secondary stimulation with specific antigen (Allardyce \& Bienenstock, 1984). However, neither topical intravaginal boosts with rMOMP, nor immunization via the presacral space achieved significant levels of antibody in genital tract secretions prior to challenge.

Some important preliminary conclusions can be drawn. Firstly, it appears that rMOMP does have some protective effect on both chlamydial colonization and subsequent tubal damage. Secondly, heterotypic protection appears to be feasible given that serovar F MOMP is quite distinct in its critical, surface-exposed, variable regions from the strain $L 1$ rMOMP antigen used for immunization (Yuan et al., 1989). Serovar $F$ is also unusual in that its species-specific epitope is surface exposed (Collett et al, 1989). This may have contributed to heterotypic protection. Thirdly, there was no evidence that vaccination with rMOMP showed the same tendency as vaccination with viable organisms of increased disease severity on subsequent challenge with live chlamydiae. Finally, mucosal and parenteral immunization appeared to have distinct effects on chlamydial colonization and tubal damage, respectively. Either effect would be valuable for controlling human infertility and ectopic pregnancy due to chlamydial infection.

Further experiments are necessary to enhance the weak protective effect of rMOMP. One strategy currently being explored is the incorporation of type-specific neutralizing epitopes into the recombinant vaccine, either by recombinant DNA techniques or by crosslinking synthetic peptide epitopes onto a MOMP backbone. An alternative strategy is the use of live vectors which stimulate mucosal immunity by their persistent presentation of recombinant antigen. The recent engineering of MOMP epitopes into recombinant E. coli enterotoxoid (Hayes \& Clark, 1990) so that they bind to the antigen-presenting $M$ cells of the gut, is one such strategy. The present experiments indicate that rMOMP, suitably presented, is capable of eliciting weak protective immunity. The challenge is to augment protection to useful levels.

We thank Professor David Taylor-Robinson, Division of Sexually Transmitted Diseases, the MRC Clinical Research Centre, for encouraging this collaborative study. Drs Mark Pickett and Ian Clarke in Southampton kindly made available $E$. coli expressing rMOMP. We thank Chris Inman of the Electron Microscope Unit, Southampton General Hospital, for the electron micrographs. Parts of this work were supported by grants from the Human Reproduction Programme (Infertility Task Force) of the World Health Organization (Geneva), the Edna McConnell Clark Foundation (New York) and SAREC (Stockholm), the Swedish Agency for Research Cooperation.

\section{References}

Allardyce, R. A. \& Bienenstock, J. (1984). The mucosal immune system in health and disease with an emphasis on parasitic infection. Bulletin of the World Health Organization 62, 7-25.

BaEhr, W., Zhang, Y.-X., JosePh, T., Su, H., Nano, F. E., Everett, D. E. \& CALDWELL, H. D. (1988). Mapping antigenic domains expressed by $C$. trachomatis major outer membrane protein (MOMP) genes. Proceedings of the National Academy of Sciences of the United States of America 85, 4000-4004.

BaRnes, R. C., Roddy, R. E. \& STAMm, W. E. (1986). Serovars of C. trachomatis causing repeated genital infection. In Chlamydial Infections, Proceedings of the Sixth International Symposium on Human Chlamydial Infections, pp. 503-506. Edited by D. Oriel, G. Ridgway, J. Schachter, D. Taylor-Robinson \& M. Ward. Cambridge: Cambridge University Press.

Bavoll, P., Ohlin, A. \& Schachter, J. (1984). Role of disulfide bonding in outer membrane structure and permeability in Chlamydia trachomatis. Infection and Immunity 44, 479-485.

Chow, W. H., Daling, J., Cates, W. \& Greenberg, R. S. (1987). Epidemiology of ectopic pregnancy. Epidemiology Reviews 9, 70-94.

Collett, B. A., Newhall, W. J., V, Jersild, R. A., JR \& Jones, R. B. (1989). Detection of surface exposed epitopes on Chlamydia trachomatis by immune electron microscopy. Journal of General Microbiology 135, 85-94.

Conlan, J. W., Clarke, I. N. \& Ward, M. E. (1988). Epitope mapping with solid phase peptides: identification of type-, subspecies-, species- and genus-reactive antibodies on the major outer membrane protein of C. trachomatis. Molecular Microbiology 2, 673-679.

Conlan, J. W., Ferris, S., Clarke, I. N. \& Ward, M. E. (1990). Isolation of recombinant fragments of the major outer membrane protein of Chlamydia trachomatis: their potential as subunit vaccines. Journal of General Microbiology 136, 2013-2020.

HAYES, L. J. \& ClARKe, I. N. (1990). Chlamydia trachomatis MOMP epitopes expressed as fusions proteins with Escherichia coli heat labile toxin subunit $\beta$. In Chlamydial Infections, Proceedings of the Seventh International Symposium on Human Chlamydial Infections, pp. 265-268. Edited by W. Bowie, H. Caldwell, R. Jones, P. Mardh, G. Ridgway, J. Schachter, W. Stamm \& M. Ward. Cambridge: Cambridge University Press. 
LuCERo, M. E. \& Kuo, C. C. (1985). Neutralization of Chlamydia trachomatis cell culture infection by serovar-specific monoclonal antibodies. Infection and Immunity 50, 595-597.

Morrison, R. P., Belland, R. J., Lyng, K. \& Caldwell, H. D. (1989). Chlamydial disease pathogenesis. The 57-KD chlamydial hypersensitivity antigen is a stress response protein. Journal of Experimental Medicine 170, 1271-1283.

Parr, E. L. \& Parr, M. B. (1988). Anti-bacterial IgA and IgG in mouse uterine luminal fluid, vaginal washings and serum. Journal of Reproductive Immunology 13, 65-72.

Picketr, M. A., Ward, M. E. \& Clarke, I. N. (1988). High level expression and epitope localisation of the major outer membrane protein of Chlamydia trachomatis serovar L1. Molecular Microbiology 2, $681-685$.

Robertson, J. N. \& WARD, M. E. (1988). Gonococcal and chlamydial infection in infertility and ectopic pregnancy. Contemporary Reviews of Obstetrics and Gynaecology 1, 60-66.

Salari, S. H. \& WARD, M. E. (1981). Polypeptide composition of Chlamydia trachomatis. Journal of General Microbiology 123, 187-207.

Shemer-Avni, Y., HoltmanN, H., Wallach, D. \& Sarov, I. (1990). Cytokine-cell interactions resulting in $C$. trachomatis inhibition mechanisms involved. In Chlamydial Infections, Proceedings of the Seventh International Symposium on Human Chlamydial Infections, pp. 173-176. Edited by W. Bowie, H. Caldwell, R. Jones, P. Mardh, G. Ridgway, J. Schachter, W. Stamm \& M. Ward. Cambridge: Cambridge University Press.

Stephens, R. S., Wagar, E. A. \& Schoolnik, G. K. (1988). High resolution mapping of serovar-specific and common antigenic determinants of the major outer membrane protein of $C$. trachomatis. Journal of Experimental Medicine 167, 817-831.

Su, H., Zhang, Y.-X., Barerra, O., Watkins, N. G. \& Caldwell, H. D. (1988). Differential effect of trypsin on infectivity of $C$. trachomatis: loss of infectivity requires cleavage of major outer membrane protein variable domains II \& IV. Infection and Immunity 56, 2094-2100.

TAYLOR-ROBINSON, D. \& WARD, M. E. (1989). Immunity to chlamydial infections and the outlook for vaccination. In Vaccines for Sexually Transmitted Diseases, pp. 67-94. Edited by A. Meheus \& R. Spier. London: Butterworths.
Thomas, B. J., Evans, R. T., Hutchinson, G. K. \& Taylor-Robinson, D. (1977). Early detection of chlamydial inclusions combining the use of cycloheximide-treated McCoy cells and immunofluorescence staining. Journal of Clinical Microbiology 6, 285-292.

Tuffrey, M. \& Taylor-Robinson, D. (1981). Progesterone as a key factor in the development of a mouse model for genital-tract infection with Chlamydia trachomatis. FEMS Microbiology Letters 12, 111-115

TUfFrey, M., Falder, P., Gale, J. \& TAylor-Robinson, D. (1986a). Salpingitis in mice induced by human strains of Chlamydia trachomatis. British Journal of Experimental Pathology 67, 605-616.

Tuffrey, M., Falder, P., Gale, J., QuinN, R. \& TAYlor-Robinson, D. $(1986 b)$. Infertility in mice infected genitally with a human strain of Chlamydia trachomatis. Journal of Reproduction and Fertility 78, 251-260.

Tuffrey, M., Alexander, F., Inman, C. \& Ward, M. E. (1990a). Correlation of infertility with altered tubal morphology and function in mice with salpingitis induced by a human genital-tract isolate of Chlamydia trachomatis. Journal of Reproduction and Fertility 88, 295305.

Tuffrey, M., Alexander, F. \& Taylor-Robinson, D. (1990 b). Severity of salpingitis in mice after primary and repeated inoculation with a human strain of $C$. trachomatis. Journal of Experimental Pathology 71, 403-410.

Ward, M. E., Bailey, R., Lesley, A., KajbaF, M., Robertson, J. \& MABEY, D. C. W. (1990). Persisting inapparent chlamydial infection in a trachoma endemic community in the Gambia. Scandinavian Journal of Infectious Diseases Supplement 69, 137-148.

W ashington, A. E., Johnson, R. E. \& SANDERs, L. L. (1987). C. trachomatis infections in the United States: what are they costing us? Journal of the American Medical Association 257, 2070-2073.

Yuan, Y., ZhaNG, Y.-X., WatKINS, N. G. \& CALDWELl, H. D. (1989). Nucleotide and deduced amino acid sequences for the four variable domains of the major outer membrane proteins of the $15 C$. trachomatis serovars. Infection and Immunity 57, 1040-1049.

Zhang, Y.-X., Stewart, S., Joseph, T., TaYloR, H. R. \& Caldwell, H. D. (1987). Protective monoclonal antibodies recognize epitopes located on the major outer membrane protein of Chlamydia trachomatis. Journal of Immunology 138, 575-581. 